\title{
Overtranslation, Undertranslation and Loss of Meaning
}

UDAYA NARAYANA SINGH*

\section{Introduction}

In this essay, we discuss the problems and obstacles that often mar the joys of reading literary texts which goes by the name of 'under translation' (or alpaanuvaad in Indian languages). Alternatively, in translation either because the text generated has fallen far short of expectations, resulting in the process in a zeal to replicate the source text, translators overdo their bit and come up with a target text which one could call a product of the process of 'overtranslation' (atyanuvaad).

Notice that what is said here applies only to such texts which are created not as adaptations or revisions, which many 're-creators' may rightfully claim, have independent existence. This is not to deny that at times, a given rendering or 'adaptation' may achieve a rare status or a beauty that might not have been associated with the original, making it possible to gain a literary fame on its own merit. This would, however, be an example of 'gain of meaning' (which we could call arthaagam), whereas what actually happens in almost all inter-lingual rendering is 'loss of meaning' (= artharaas).

\subsection{Literary vs Literal: Problem of Definition}

Early translation scholars have been concerned with 'literariness' (= saahityikataa) of the resultant texts or with 'Primary' and 'Secondary' sources (= mukhya vs gauNa srota) of translation, before they actually begin to 'appreciate', 'evaluate' or 'analyse' a literary text in translation. In reading and understanding a literary text in translation, we cannot afford to repeat such wornout practices.

Long ago, I.A. Richards (1929) suggested that a new theory of appreciation should allow individuals trying to understand a text to

\footnotetext{
* Prof. Udaya Narayana Singh is the Director, Central Institute of Indian Languages, Mysore.
} 
discover themselves while trying out new discovery procedures for what he called a 'perfect understanding' of the text. If we now look back at his ideas and argue that 'perfect' understanding is only an illusory concept, then it will follow that a 'perfect' translation could only be a theoretical possibility. The general impression is that the moment we begin to read literary translations, particularly if we also happen to know the original work, the deviations stand out before us very clearly. Thus sometimes there are unavoidable operations or changes performed on the body of target texts that are rooted deeply in a very different cultural tradition. Such changes are also a part of a strategy to circumvent a virtually 'untranslatable' portion, the knowledge of which may or may not come with the experience one has had with the writings on translation theory. On some occasions, however, they may simply appear to be sheer ingenious manipulations. But then, many translators are not all apologetic about such manipulations. When this happens, some still remain upset with their own recreations or rewritings, which have thus undergone a thorough. metamorphosis, while there are others who take it as their divine duty to 'improve' upon the original. One cannot forget the arrogant remark of Fitzgerald, the well-known translator of Omar Khayyam, who once commented that "it is an amusement to me to take what liberties I like with these Persians who (as I think) are not Poet enough to frighten one from such excursions and who really want a little art to shape them (Fitzgerald to Rev. Cowell)".

Quite in contrast is an Indian poet who, through an excellent poem, tries to define the tremendous responsibility of the translator through these lines, which are self-evident:

Poetry translation is a transfiguration. as a fish dives through water the translator moves through minds. On the bank of each word, in the thick sand, he kneels, studying the colour of each shell, blowing each conch. 
Poetry translation is

the embarrassing head-

transposal of the Vikramaditya

tales. The translator

supports another poet's head on his trunk. Each line

is a lane worn out with

war, misery and boredom.

A bylane of music along which

parade immortal men, gods

and trees. An abyss opens

where a line ends. The souls

of the dead quench their thirst

in that pool of silence.

O, Those who come this way, please remove your footwear

and leave your arments here.

You must sneak through naked, like the wind in the valley.

One day I dreamt of myself translating my poetry

into my own private language.

All of us translate each poem into my own private language and then we quarrel over the meanings.

It seems to me that the Babel will never be complete.

(K. Satchidanandan: 'Translating Poetry', tr. By E.V. Ramakrishnan, Chandrabhaagaa II, Vol. II, 1984, pp. 39-40)

\subsection{Translation as Rewriting: Accolades and Brickbats}

The moot question is not whether have any right to deviate . by deliberately undertranslating texts or by bringing in 'suppletions' or substitutions. Rather the question is whether such deviations can also lead to literary innovations on its own right, and 
if so, can involve rewriting inevitably. Recall what Basnett and Lefevere said:

"Translation is, of course, a rewriting of an original text. All rewritings, whatever their intention, reflect a certain ideology and a poetics and as such manipulate literature to function in a given society in a given way. Rewriting is manipulation, undertaken in the service of power, and in its positive aspect can help in the evolution of a literature and a society".

There are times when a translator who is himself a powerful writer and has original genius accepts, quite voluntarily, a 'subordinate' role in allowing the transposition of an original author in his or her language. We know about the Spanish ballads in English mainly through Byron's versions. When Wilhelm Meister was translated by Carlyle, he freed the resultant text from the mannerisms and tricks of the original. Such interests as the English nation has been induced to take in German literature dates from the appearance of Carlyle's translation. Such could be the influence of a translation. What the world knows as Illiad and Odyssey today exist, thanks to the excellent, but sometimes quite creatively deviant, efforts by Pope who brought them out in 1715-20 and 1715-26, respectively. In fact Dryden said very clearly about what should be an ideal aim of a literary translator in the following words:

"A translator that would write with any force or spirit of the original must never dwell on the words of his author. He ought to possess himself entirely, and perfectly comprehend the genius and sense of his author, the nature of the subject, and the terms of the art or subject treated of; and then express himself as justly, and with as much life, as if he wrote an original; whereas he who copies word for word losses all the spirit in the tedious translation".

But at times a translator is also subjected to unkind remarks because of the deviations he/she makes. Take, for example, the case of Charles Jarvis' translation of the famous Spanish text Don Quixote (1742) which appeared after Jarvis passed away. There was a malicious theory which apparently Pope was supposed to have 
authored when he commented, according to Warburton, that 'Jarvis translated Don Quixote without knowing Spanish'. Notice that this was a comment on a translation which has been reprinted innumerable times since its first appearance, and this was what has made Cervante's masterpiece known to so many generations. The comment which was wholly untrue, was only a reaction against the changes and modifications made. Whatever we may say about Edward Fitzgerald's attitude to the original Persian writing, it is still a fact that he would be remembered not as a translator of Sophocles into English, but as someone who transfigured, if we may say so, through his version of 'Rubaiyat' (1859), Omar Khayyam a medieval Persian poet to an English genius of the nineteenth century. Another translator, Arthur O'Shaughnessy in his rendering of 'Lays of France' (1872) follows suit, and charts an independent course as he elaborates, paraphrases and embroiders rather than translating the 'Lais' of Marie de France.

Notice that translated literatures have sometimes been responsible for major literary movements. The influence of Ibsen in translation which has changed the dramatic method of the modern stage in the European context earlier, or the translation of a dramatic genius like Brecht into different Indian languages are examples of this point. But a more apt instance can be found in the powerful impulse provided to the Romantic Movement in the continent by Voss' translation of 'Odysse' (1781) and 'Illiad' (1793) and A.W. Von Schlegel's renderings of Shakespeare over a thirteen-year period (1797-1810).

\section{The Text and The Work}

Some structuralists interpret reading of a literary text as a productive and creative. Rather than viewing the reader of a text at the end of the line, waiting to 'receive' a text or a work and 'receive from' it pleasure, pain, fun, directions, advice or even responses to questions that he always wanted to ask but dared not ask, the reader is viewed as reading to produce 'interpretations', to create histories, ideas, mores, sciences and systems that are as valuable as the text itself. A reader always rewrites the texts, and he comes back to do so again and again, because every time he writes it, the text appears ever more 'writable'. He does so because he is able to mimic the 
creative process that was the cause of the writing of this given text in the first place, without worrying about the accuracy or otherwise of the reproduction or rewriting. Thus, texts are scriptable by definition, notice that here the reverberations available in a text are more important than the thing itself, as Mallarme had put it long back.

In comparison, works are extremely 'readable' objects which are not written again and again. They are only to be read and enjoyed. They are only to be consumed, as it were words in these works move from a definite point to another definite or 'appointed' end, and hence they captive the readers. That means that all works of certain standard or value are extremely 'lisible' but rarely 'scriptible'. Obviously, another important point of difference between the text and the work is that the latter fades more rapidly than the former. The text lives through different ages and outlooks, and, at times, even written in different languages. The RaamaayaNa text provides one of the best examples of this. All the works that are a kind of response to the text of the Raama-Siitaa or the RaamaRaavaNa story written in Awadhi, Bengali, Maithli, Telugu, Tamil, and a host of other languages, including languages used outside India (e.g. Thai) are works as well as different readings of the same text. Just as these could be interpreted in one sense as translations or as 'trans-creations', in another sense they provide us with a kind of creative reponse provided by (readers of texts) with extraordinary literary skills (such as Tulsiidaasa, Krittivasa or Kamban, etc).

\subsection{Translation as Interpretation}

It is important for us to understand in what literary translators are capable of positively contributing to literary appreciation and criticism, sometimes more than the monolingual conventional critic. Notice that more often than not, the typical critical analysts believe in a set of moral and formal values of the texts and works to be interpreted-values that are supposedly 'eternal'. In contrast, the translator, in trying to go through the twin processes of 'comprehension' and 'formulation', first tries to find out - not about the morality or the formal structure of the text - but about a series of wh-questions about its origin, function and future. In 
particular, he would like to know: who wrote the text and under what socio-political conditions; who were/are its readers and what were their social compositions; and at which point of time the text emerged. Secondly, a typical critic will look for a wholistic meaning in a text, i.e., look for 'the' meaning, not caring to appreciate that language (and consequently, literature, too) could be ambiguous.

Secondly, although critics may consider the search for alternative meanings or supplementary meanings futile, or although they may, at the most, restrict themselves to only a few apparently legible interpretations self-evident from several cues that the author may have provided, literary translators are not bound by any of these guileless and simplistic interpretations. This is because they are not only interpreting the original text, they are reading it to reread and re-create. They are finding meanings in a text in relation to the world of meaning of the target language semantics as well as in terms of its possible readings (which each one of them thinks is possible) in the source culture and community.

Thirdly, since ten different translators are likely to give ten different translations, based on many differing interpretations, this appreciation of ambiguity is ingrained in the approach of a literary translator. In fact, it is now increasingly realised that one can only interpret a literary text only if one dares attempting to render it interlingually, inter-semiotically or even intra-lingually, although the third approach is usually uninstantiated. Notice that some of the best critiques of a literary text have come from their cinematic renderings (hence, inter-semiotically).

\subsection{Reading of Literary Textș: The Anomaly}

When we discuss the problem of the reading of literary texts, an interesting anomaly comes to the fore. Consider, for instance, what the well-known fiction write Jorge Luis Borges tells us about the mysterious language of Tlonans. He paints the Tlons as people from another planet who talk without nouns, because the world for them is a heterogonous series of independent acts'. Equivalents to nouns in the language of Tlons work with impersonal verbs modified by monosyllabic suffixes having adverbial function. For instance, here as a word 'translation' will be an impossibility, but 'to translate' is 
perfectly possible. That is the kind of confusing situation that translation theoreticians have to deal with. The example used by Tirumalesh was of course different: 'moon' (being an impossible construction) versus 'to moonate' (being perfectly possible). As we have seen with various paradoxes in the theory of translation, it applies on the verb (='to translate') in which, we are interested in, too.

At this point, it is educative to recall what is known as the Sapir-Whorf hypothesis which claims that language acts as a grid, or a vetana to look at the world outside, i.e., it will structure, classify, assign truth values, determine presuppositions or colour our perception of the world, just as our culture would determine what kind of language we will have or what will be its various categories, derivational mechanisms, sentential rules, sound laws of constraints. Even if we leave out the question of lack of falsifiability of such a hypothesis, and even if it is partly true that the "the world in which different societies live are distinct worlds, not merely the same world with different labels attached", English and Hindi may be languages quite different from the world of Tlolans. In our world 'to translate' may be semantically void; otherwise, how can one explain the fact that while there is an enormous literature pointing out the difficulties, if not the impossibilities, of translating, there is also a huge repository of actual translations existing in our languages.

Add to that the examples that anybody can produce to show different two languages can be in terms of their expressive power. An impossible, illogical and ungrammatical structure in one language becomes a perfectly possible structure in another. The more we discover such language differences, the more remote seems the possibility of our reaching the declared goal of building a Universal Grammar. Some have learnt the art of getting around this problem by emphasizing that rather than talking about laws that are purported to be 'universals', one should view language structures or such seemingly opposing grammatical constructions in terms of language typology. Others have taken it as evidence for the impossibility of translation. 
It is not difficult to understand the frustration of the universalist. Just when everything seems to be going well with his theoretical predictions about the UG or with his universal hypotheses, there seems to appear, with reasonably devasting effect, a Malayalam, Maithili, Dyirbal, Malagasy, Middle Mongalian or a little known Brazilian language that upsets all generalizations of linguists and universalists. However, to draw a negative inference from the above events or from the mythical episode of Narcissus and Echo is to give up all hope of reaching any meaningful explanation of the phenomenon. It is not enough to state that languages defy generalization. Such defiance also needs to be explained.

\subsection{The Difficulties}

As for the impossibility of translation, a translator may have an aim which he may not be able to fulfil. The reasons for such a failure could be many. He may not be able to decode the text fully. This difficult-to-decode text need not be a difficult literary text alone. It can be difficult scientific or legal text too. But obviously, this is more likely to happen in the case of literary translation. This may happen even if he knows the language well.

The other possibilities are that his competence in the target language (TL) may not be the same as his knowledge of the source language (SL). Alternatively, the structure of SL and TL may be so different that even the best translators cannot do justice. And then there is danger that he may read more meaning into a text than was intended by the original author.

\subsection{The Successes}

It does not rule out the possibility that some translators may achieve their desired end, whatever that may be. There may be several factors that may contribute to such success - perceived or real. The most important of these is the knowledge of both SL and TL that a translator operates with. More often not, in such cases, the translator is a mother tongue speaker of the TL or a grass root bilingual with both languages available at home. There may be other reasons too. The translator may share the concern, philosophy, and other aspects, excluding the professional expertise, 
of the author of the text. Yet another reason for success could be that the SL and TL were genealogically and typologically close to each other.

\section{A case in hand}

\subsection{Two Texts}

The term 'success' is very difficult to be precise about in the context of literary renderings. For instance, for a long time Sukumar Roy in Bengal literature has been regarded as an impossible author and limeric writer to translate, although some of his pieces have been translated by his son, Satyajit Ray, the eminent film-maker. Still, his nonsense fables would always be regarded as a challenge for anyone would dare translating them into English or any other non-Indian language. But consider these two examples of his 'fables bilge' or 'malarkey', as they are sometimes called:

\section{Text 1A: Translation}

From Sukanta Chaudhuri 987 'Ha-ja-ba-ra-la' of Sukumar Ray (Illustrated Weekly of India, 14 June no.,pp. 36-9)

It was terribly hot. I lay in the shade of a tree, feeling quite limp. I had put down my handkerchief on the grass; I reached out for it to fan myself, when suddenly it called out

'Miaouw!'

Here was pretty puzzle. I looked and found that it wasn't a handkerchief any longer. It had become a plump ginger cat with bushy whiskers, staring at me in the boldest way. 'Bother!' I said. 'My handkerchief's turned into a cat'.

'What's bothering you?' answered the Cat. 'Now you have an egg, and then suddenly it turns into a fine quacky duck. It's happening all the time'.

I thought for a while and said, 'But what should I call you now? You aren't really a cat, you're a handkerchief'.

'Please help yourself', he replied. 'You can call me a cat, or a handkerchief, or even a semi-colon'.

'Why a semi-colon?' I asked.

'Can't you tell?' said the cat, winking and sniggering in a most irritating manner. I felt rather embarrassed, for 
apparently I should have known all about semi-colon. 'Ah!' I said quickly. "Now I see your point'.

\section{Text 2A: Translation}

From Sukanta Chaudhuri 1987 'ha-ja-ba-ra-la' of Sukumar Ray (The Illustrated Weekly of India. 21 June no, pp. 36-9)

He really was a most extraordinary creature.

'Who are you?' I asked him 'What's your name?'

He thought for a while and said, 'My name's Higgle-Piggle-

Dee. I'm called Higgle-Piggle-Dee, my brother's called Higgle-Piggle-Dee, my uncle's called Higgle-Piggle-Dee...'

I cut him short. 'Why don't you simply say the whole family's called Higgle-Piggle-Dee?'

He pondered the matter again. 'Oh no', he said at last, 'I'm really called Tokai, my uncle's called Tokai, my nephew's called Tokai, my cousin's called Tokai, my father-in-law's called Tokai...'

'Are you sure?' I asked sternly. 'Or are you making all this up?'

He grew confused and stammered, 'Well, actually my fatherin-law's called Biscuit.'

There is no doubt that both these passages independently read very well. But to consider the translated texts seriously, let us look into the original texts now in order to determine the success or failure of these two translations:

\section{Text 1B: The Original (Bengali)[Transliterated in Roman]}

From Prafulla Kumar Patra, ed. 1986. Sukumar racanaabalii; (Calcutta: Patra's Publications. 125-140), pp. 125:

bejaay garam. gaachtalaay dibyi chaayaar madhye cupcaap shuye aachi, tabu gheme asthir. Ghaaser upar rumaalTaa

chila; ghaam muchbaar jonno jei se Taa tulte giyechi amni rumaalTaa bollo, 'mEo!' ki aapad! RumaalTaa aabaar mEo kare keno? 
ceye dekhi rumaal to aar rumaal nei, dibyi moTaa-so Taa laal TakTake EkTaa beRaal go f fuliye pET pET kore aamaar dike taakiye aache.

aame bollaam, 'ki mushkil! chila rumaal, haye gElo EkTaa be Raal.'

omni beRaalTaa bole uThlo, 'mushkil aabaar ki? Chilo Ektaa Dim, haye gEla dibyi EkTaa pEk-peke haa s. e to haameshaai hocche.'

aami khaanik-khan bhebe bollaam, 'taahole tomaay Ekhon ki bole Daakbo? tumi to satyikaarer beRaal nao, aasale tumi hoccho rumaal.'

beRaal bollo, 'beRaalo bolte paaro, rumaalo bolte paaro, candrabinuo bolte paaro'. aami bollaam, 'candrabindu kEno?

shune beRaalTaa 'taao jaano naa?' bole Ek cokh bu je fEc kore bisrii rOkom haa ste laaglo. aami bhaari aprastut haye gelaam.

mane holo, oi chndrbindur kathaaTaa nishcay aamaar bojhaa ucit chilo taai thatomato kheye taaRaataaRi bole phellaam, 'o hE hE bujhte perechi.'

\section{Text 2B: The original}

From ibid, pp. 132:33:

jantuTaar rakam-sakam dekhe aamaar bhaari adbhut laaglo. aami jiggaa saa korlaam, 'tumi ke? Tomaar naam ki?' se khaanikknan bhebe bollo, 'aamaar naam hijibijibij. Aamaar maamaar naam hijibijibij, aamaar baabaar naam hijibijibij, aamaar pisher naam hijibijbij---'. aami bollaam, 'taar ceye sojaa bollei hay tomaar guSTishuddho sabaai hijibijbij'. 
se aabaar khaanik bhebe bollo, 'taa to nay, aamaar naam takaai. Aamaar maamaar naam takaai, aamaar khuRor naam

takaai, aamaar meshor naam takaai, aamaar shwashurer naam takaai -..--‘

aami dhamak diye bollaam, 'satyi bolcho? naa baaniye?' jantuTaa kEmom thatomato kheye bollo. 'naa naa, aamaar shwashurer naam biskuT'...

\subsection{Analysis}

If we compare the original passages with the two translated texts, certain semantic and structural losses become evident. Let us take the first set of texts (la and $\mathrm{lb}$ ) in original and translation first.

The first noticeable thing was that the translator has violated the norms for the use of space and silence as in the original text. The first paragraph should have ended after the sentence 'Here was a pretty puzzle', although this sentence itself was not enough for the original ' $k i$ aapad! RumaalTaa mEo kare kEno? A more literal rendering of the original would have been: 'What is happening? Why does the kerchief say: Miaouw?' But that is beside the point here, as we are not merely considering truthfulness, but are trying to pin-point losses.

Secondly, "Why a semi-colon?" I asked' should have been a part of the earlier paragraph, if it was to be like the original.

But this kind of modification was more evident in the second set of texts in $2 \mathrm{a}$ and $2 \mathrm{~b}$ : There was no paragraph division in the Bengali text where it is there in English (between the first two paragraphs in the English version). The last two paragraphs in the English text (including one more paragraph which is not quoted here which together form just one unit in Ray's Bengali original). This kind of division, except probably in poetry may be allowed, particularly because they are usually in conformity with the target language way of organizing things in fiction or such other prose texts. 
Now let us look into losses, both lexical and semantic. Expressions such as 'dibyi (=leisurely), 'tabu' (=still), 'ghaam muchaar jonno' (=to wipe out perspiration), 'cupcaap' (=quietly) etc. in the first paragraph are missing in the English version. Also, 'rumaal to aar rumaal nei' could have been replaced with the handkerchief was no more a kerchief' but the translator, for reasons that had to do with the naturalness of English syntax, opted for 'it wasn't a handkerchief any longer'. 'moTaa-soTaa laal TakTake EkTaa beRaal' became a plump ginger cat' which was indeed the best in this situation. But how on earth does one translate ' $p E T$ PET kore...taakiye aache' (in la: 'staring at me in the boldest way')? It is not mere 'boldness'; add to that 'mischievousness', 'repudiativity', 'inquisitiveness' and 'plainness', because had it been mere 'boldness', a back translator (from English into Bengali) would render it as ' $k O T$ kOT kore...'. Also missing in English is the alliterative 'chila rumaal, haye gElo EkTaa beRaal', even though 'ki mushkil?' has been aptly converted into 'Bother!'

In considering changes, however, we find a number of significant alterations - some required because of linguistic and cultural differences, some others not so necessary. For instance, in the first text, the alternative name offered by the ginger cat was not 'Semi-colon'. That was surely a suggestion of the 'chandrabindu'. The pedantic nasalization mark or not so scholary 'nasal accent' do not come anywhere near the original word which carries a lot of associative meaning because of the way it looks in the Bengali writing system. Such connotations are difficult to render. Similarly, the translator had to take hard decisions on what to call a number of Ray originals which can be enlisted below:

\subsection{Glossary \& Further Discussion}

$\begin{array}{ll}\text { a. } \text { moTaa soTaal laal TakTake EkTaa beRaal } & =\text { ginger cat } \\ \text { b. } p E \sim k p E \sim k e \text { haa } \sim \text { Ms } & =\text { quacky } \\ & \text { duck } \\ \text { c. cnadrabindu } & =\begin{array}{c}\text { semi- } \\ \text { colon }\end{array} \\ \text { d. gechodaadaa } & =\text { Cousin } \\ & \text { Treehooper }\end{array}$


e. gechodoudi

f. daa Rkaak

g. baRamantrii

h. paatra mitra

i. Daaktaar

j. gechobaajaar, kaageyaapaTi

k. paatikaa, heRekaak, raamkaak

l. udho..budho

m. hijibijibji

n. shribEkaraN shing

o. nERaa

p. jholaa pOraa hutom pE caa

q. baaduRgopaal

r. mejomaamaa

s. bORomaamaa
$=$. Treehooper's

- wife

= Jungle-crow

$=$ the Head Vizier

$=$ pastors and masters

$=$ doctors and proctors

= Raven Row, Woodmarket

$=$ House-crow, Gor-crow and Carrion Crow

= Other... Brother

= HigglePiggle-Dee

$=$ Grammaticus Horner

$=$ Smoothpate

= Screech-owl in a long gown

$=\mathrm{Bat}$

$=$ Uncle

$=$ Uncle

The last two 'uncles' have entirely different roles to play but one finds it very difficult to translate kinship terms from Indian languages into English anyway. As we can see in Text $2 \mathrm{a}$ and $2 \mathrm{~b}$ 'pishe', 'maamaa', 'khuRo', 'mesho' in the dialogue of Higgle- 
Piggle-Dee were avoided by the translator. Instead, he chose: 'uncle', 'uncle', 'nephew', and 'cousin', respectively. This is a typical problem with a culturally different text. The translator was obviously aware that ' $k h u R o$ ' (= father's younger brother) and 'mesho' (= mother's sister's husband) cannot be equated with 'nephew' and 'cousin', but there had to be different kin words (other than the generic 'Uncle' for all) to make this part of the text effective, and there aren't that many terms in English. Similarly, while the transfer of ' $n E R a a$ ' into 'Smoothpate' in 2.3(o) above was smooth, 'baaduRgopaal' cannot be adequately covered under a simple 'Bat'. The translator very intelligently used expressions such as 'higgle-Piggle-Dee, 'Croworthy Cole-Black' as well as various classifications of crows (=Corvus Sylvanus, Jungle-Crow, Gorcrow, Raven-crow and Carrion Crow), but a number of other names probably were not possible to handle equally deftly. This included 'gechodaadaa', majaaru' or 'baaduRgopaa;l', etc. The blooperous rendering was of course in the fourth paragraph in $2 \mathrm{a}$ which starts the 'Tokai' narration but makes a costly mistake. There is a logic in what the Higgle-Piggle-Dee says, just as there is a logic in the concept: 'Ha-ja-ba-ra-la'. He does not and cannot say that his name was 'Tokai'. As anyone can see in $2 \mathrm{~b}$, he says that his maternal uncle (and various other relatives) is called 'Tokai', which he says to counter the allegation of the listener (=the self), viz. that Higgle-Piggle-Dee better says that the whole clan ('gusTishuddho') is called Higgle-Piggle-Dee'. Therefore, the sentence spoken after the creature pondered for a while cannot start with I'm really called Tokai'. I don't think this was a chance error.

The probability was that the translator was doing what is called 'saving' (or, improving upon) the text' by trying to forge a link between the two apparently senseless statements of the HigglePiggle-Dee. But if one thinks about it seriously, now that we know a little more about the endlessly different and creative manners in which human languages show semantic and grammatical categorization of any concept, it isn't entirely impossible to think of a culture where naming patterns have such rules as given by our hijibijibij here. Thus, it is perfectly possible for different kinds of people in your little world to have three sets of names : hijibijibij, Takaai and biskuT. 
To come back to the first text, although most readers would point out that the expression ' $h a$-ja-ba-ra-la' in Bengali has now become synonymous with 'hijibiji' or hijibijibij', i.e. in English nonsense, fiddlesticks or poppycock. I think there is a deeper logic in the name. This is possible to appreciate if one considers the apparently crazy (but actually very scientific) organization of the sound system or varNas in the great grammar of Panini written 2500 years ago. Notice that Panini's 'shivasuukta' had fourteen 'words', the last two being: hayavaraT; laN, which is what gives us ' $h a$ ya va ra la' (In Bengali, the Sanskritic ' $y a$ ' becomes ' $j a$ '). One who does not know the Indian grammatical tradition would probably miss out the simile intended by the author.

The above discussion makes one point pretty clear, namely that even if one takes the translation of very high quality, there is bound to be a semantic loss, gap or mismatch. That takes us to the next section which addresses multiple texts showing different kind of losses. This discussion is very minimal, because as students of translation, the losses would be easily perceived by all of us.

\section{Loss of Meaning}

\subsection{Problematic Areas}

As Newmark rightly points out, the translator is a victim of a constant tension between the acts of overtranslation and undertranslation. A lot of semantic gaps in translated texts arise because of this tension.

Yet another set of possible problems arises if the SL text has a situation peculiar to the nature and culture of the SL speech community. A translator then has to decide whether he should (i) transcribe (ii) translate, (iii) substitute with something similar from TL, (iv) naturalize, by making minor modifications (be they grammatical or phonological), (v) by loan translating, or (vi) by paraphrasing. If SL and TL differ lexically, grammatically and phonologically at both langue and parole levels there is bound to be a loss, especially at the lexical level. 
Again, individual uses of language (although SL and TL are different) of the author and the translator may not coincide. Idiosyncrasies and private meanings may cause losses.

Further, the author and the translator may have different theories of meaning. Differences may occur in what each one of them values more than anything else:

Denotation or Connotation

Symbolism or Realism (any other 'ism'-related differences)

Multiple Vs. Single interpretation

\subsection{Texts and Examples}

Let us take up a few typical examples of each of these problems. But we can start with the two dangers that a translator has to tread upon all the time - the dangers of overtranslation and undertranslation.

\subsubsection{Overtranslation}

The first instance we have given a poem (or song) from 'Aruup ratan' ('Formless Jewel', see Ananda Lal's translation) of Tagore which goes as follows:

\section{Text 3A: The Original (Bengali)}

mama cite niti nritye ke ye naace

taa-taa thai-thai, taa-taa thai-thai, taa-taa thai-thai.

taari sange kii mridange sadaa baaje

taa-taa thai-thai, taa-taa thai-thai, taa-taa thai-thai.

hassi-kaannaa hiraa-paannaa dole bhaale.

kaa pe chande bhaalomanda taale taale, naace janma naace mritya paache paache taa-taa thai-thai, taa-taa thai-thai, taa-taa thai-thai, kii aananda, kii aananda, kii aananda

dibaa-raatri naace mukti naace bandha, se tarange chuTi range paache paache taa-taa thai-thai, taa-taa thai-thai, taa-taa thai-thai. 
While rendering it into English, Father C.F. Andrews tried to overdo as a translator (as noticed quite early by Surendranath Dasgupta in his review of 'rakta karabi') when he translated the above lines as follows:

\section{Text 3B: Translation 1}

"In my glad heart, in my mad heart, who is dancing? Ding a ding dong, ring a ting tong, ding a ding dong Where no fears are, joy and tears are ever glancing, Ding a ding dong ...

Where the music rises higher, like a fire,

Now advancing, all entrancing, joy enhancing Ding a ding dong ...

Pain and gladness, smiles and sadness, toil and leisure Night and morning, light and dawning, full the measure Ding a ding dong ...

Oh the pleasure, oh the pleasure, oh the pleasure Of our dancing, ever glancing, all entrancing Ding a ding dong ...

Like the Oceans in its motion waves are Fears are groundless, freedom boundless, life is waking With our dancing, ever glancing, joy enhancing Ding a ding dong ..."

Consider what a recent serious translator of Tagore such as Ananda Lal had to say about such overtanslations: 'Such a translation can only provoke laughter. The meticulous attention paid to rhyme and metre replicates the original Bengali technique but does not possess any vitality of its own, and the jejune refrain kills whatever little life the song had". The translation that Lal himself provides of this text is free from this tension. 


\section{Text 3C: Translation 2}

Who dances in my heart the dance eternal?

What mridanga beats with it incessantly?

Smiles and tears, emeralds and diamonds, swing in fate.

Good and bad vibrate to the rhythm, keeping time, Birth and death dance at one another's heels.

What happiness, what happiness, what happiness.

For freedom and confinement dance all day and night

I flow with those ways, joyful, at their heels.

\subsubsection{Losses}

Let us consider some examples of the possible losses. The next two texts are from the Sumati-sataka, written in Telugu (a part of Niite-satakas, others being Kumara Sataka, Kumari Sataka, Kanta Sataka, Suniiti Sataka and Vemana Sataka; by Baddenna of $12^{\text {th }}$ century):

\section{Text 4A: The Original (Telugu)}

adharamunu kadala niyyaka

The lip without letting move

madhuraamruta bhaasaa ludigi maunasthundai nector-like-sweet speech having died keeping silent down

Yadhikara rooga puurita Authority sick filled

badhiraandhaka savamu juuda paapamu sumatii deaf and blind corpse to see sinister $\mathrm{O}$ man with good sense

\section{Text 4B: Translation 1 (C.P. Brown 1842)}

He moves not his lips! He refrains from words flowing with honey and nectar. He, a solitary, deaf, and blind corpse swollen up with the disease of authority, is indeed a shocking object. 


\section{Text 4C: Translation 2 (Srinath and Subba Rao 1987)}

Feigning speech but tight-lipped

withholding sweet word in stony silence

he is a power-swollen corpse -

deaf and blind, to sight him is sin, O Sumathi!

\section{Text 4D: Translation 3 (UNS)}

The lips move not

Speech-sweet as nectar, die down; is mum.

O man with good sense! It is indeed sinful

to see a deaf and blind corpse -

filled with disease of authority.

\subsubsection{Undertranslation}

An example of undertranslation comes from Thomas Fitzsimmons' translation of a ghazal of Ghalib's as given in Aijaz Ahmad's book (1971: 25) which reported on an experiment to get poems translated by monolingual poets through the well-defined mechanism of using an intermediate literal translation plus a detailed commentary forming the bases. The original ghazal of Ghalib in Urdu reads like this in its first two couplets:

\section{Text 5A: The Original}

Ishrate qatraa hai daryaa mẽ? fanaa ho jaanaa,

Dard kaa had se guzarnaa hai dard kaa dawaa ho jaanaa.

Jaã fase gariye mubacchal badme sard huaa

Baavar aayaa hamẽ? paanii kaa ho jaanaa.

Original explanation or the philosophical import is not difficult to understand. The first couplet means that to be consumed by the whole can be the ultimate joy of the part, just as pain becomes its own medicine. The second one tells us that we can only sigh and not weep at our weakness once it crosses certain limits, which is why one can now believe that water (=tears) can become air (=sigh) - comparable to the process of cloud-formation. The literal 
translation of Ahmad, though not claiming to be poetic, seems to capture the above meanings aptly:

\section{Text 5B: Translation 1}

"The happiness of the drop is to die in the river;

When the pain exceeds bearable limits, the pain itself becomes the medicine.

Our weakness is such that tears have turned mere sighing Now we really believe that water can turn into air".

Let us consider a target poet's translation of this important poetic text:

\section{Text 5C: Translation 2 (Thomas Fitzsimmons; cf. Ahmad, pp.25)}

"Waterbead ecstasy: dying in a stream;

Overtranslation, Undertranslation and Loss of Meaning

Too strong a pain brings it own balm.

So weak now we weep sighs only;

Learn surely how water turns into air".

First, the text may describe a situation peculiar to the environment of the particular speech community or its 'peculiar' social setting which to us may seem peculiar and odd about may not actually be so. In such contexts, whatever strategy one adopts (transcription, substitution, naturalization or translation), the translated text is bound to leak in one respect or another. I would like to give here two different pieces, both in English - one translated by a western translator and the other being a product of a group translation where all the members of rendering cultural items or culturally-sensitive texts.

Consider this brief piece of translation without the original (far a better appreciation of this point) from a 1956 poem by Suryakant Tripathy 'Nirala' in translation: 


\section{Text 6: Translation from Hindi (Title: 'Love Song')}

I'm a Brahmin's son

And I love her.

She belongs to the Kahars

And at the first crack of light

She brings the water-jugs to my house,

And I'm dying for her.

She's black as a cuckoo, oh,

Her walk straight and steady

And not yet married. My heart

Bursts with wanting her.

She comes every day and wakes us all

But I'm the only one who understands her game.

She takes away the big water jug

And I bide my time.

(From David Rubin's Selected poems of Nirala: A Season on the Earth; Columbia U. Press, New York)

If such texts are placed before a Western reader, one cannot expect that they will be fully appreciated, because the reader concerned may not be able to understand the natural and social background of this piece. One will naturally fail to understand with what magic the tedium of the village-belles bringing water-pitches from a long distance is transformed into an aesthetically glorious visual that a male beholder longs to cerebrate and ruminate it again and again, day after day. Besides, a culture and society that does not have a caste-based stratification will miss out some other aspects of the relationship between the two here - the hero, a Brahmin - and the woman, a Kahar.

\subsubsection{Contextualizing the text}

The next text is again deeply entrenched in the environ and society it belongs to. Any Indian reader reading it in English will 
surely have a better chance of its fuller appreciation. The swear words used, or comparisons such as 'Mallarme'> 'Mallar-Meta' (in the pattern of 'Narsingh-Me(h)ta'), the fun intended to be made out of Kafka> Kofka, or the Sardar-ji being referred to will be difficult, if not impossible puns for a British English or an American English reader to appreciate. Obviously, the Indianism about expressions such as 'all wanting to leave', etc. are intended here. Consider the following longish poem by Sitangshu Yashachandra translated from Gujarati by Saleem Peeradina, Jayant Parkh, Rasik Shah and Gulam Mohammed Sheikh (Again, only English version is given to make the point):

\section{Text 7: Translation from Gujarati (Title: Magan's Insolence)}

1

It all started with stubborn Magan saying

I want to live.

The Gujarati literati were dumbfounded:

You dolt, is that ever possible?

The young clamoured on one side - what about

our experimental periodicals?

On the other the elders rebuked - this

way centuries may pass idly.

All agreed upon this - if you choose to live

then quit the sanctum of literature.

Done, said Magan.

The moment he stepped across the threshold a miracle occurred.

From the niche appeared the Goddess Saraswati and informed the king that where Magan went she would follow. And behind her - Goddess Experiment, Miss Realism, Mr. Rythem - all wanting to leave, all adamant.

So they decided, all right, you trouble-maker, stay and rot in that corner. 
But the fellow whose name was Magan, a few days later says I want love.

All right, you nut.

So we took him to Apollo Street.

In the picturesque square, an impressive building. In the building

a secret chamber under lock and key.

Took Magan to the state Bank's safe-deposit vault as stated in the scriptures, brought a priest

Overtranslation, Undertranslation and Loss of Meaning along to recite mantras

- handed one key to Magan and kept the other.

Then with chant of glory to

Ramachandra, Sita's spouse, opened the locker.

Here, take love.

But the son of a bitch Magan says - this is not love.

If this is not love then what is it, you

bastard?

All the bigwigs - prize-winners, medallists - have taken love for their stories, poems and plays

from this very source.

And you, fancy idiot, claim that this is not love.

What is it? If this is not love what is it?

What is the purpose of keeping it in the safe-deposit vault then?

So you can use it when necessary and return.

It never goes out of style.

All those veteran professors use it year after year and some of them have used it for twenty-five years - yet it stays brand new.

But

this prick Magan, he says -

I want to live and I want to love. 
Well then.

Crazy Magan was locked up in the House of Letters.

The place has western-style latrines.

In the morning everybody used paper.

Need a lot of paper: but that Sardarji

from the Times of India distributed huge rolls

of paper which were left hanging there.

Then all the literary big-shots

-old and new-

put their signatures at the bottom of the

paper after use.

And the contents would be published in periodicals or read over Akashvani.

In the case of an upset after bad food.

an entire novel could be serialized.

On anniversaries and festive occasions, special numbers and anthologies would be brought out from this stock only.

This swine of a Magan did his work really well.

Early every morning, he would do the job and forget to sign.

But those literature-loving editors would always be lurking around.

They would grab a new poem (even if it had been discarded)

and print it under the name of Magan, poet extraordinary.

Only rarely would they put their own signatures.

(Generally speaking, there is some ethics in our Gujarati literature. No one would pinch another's poem.) 
And within a year, Magan got the State prize and five or six gold medals.

And then there were celebrations and felicitations: Every paper announced that on a certain date and day, a felicitation programme for Magan, the poet emeritus, would take place with the following speakers and who the chairman would be, plus a long list of well-wishers.

Each one of them spoke, What oratory! Some mentioned Kofka, another spoke of Mallarmeta and still another of Narsinhmeta. Someone spoke of the love between a camel and a cow.

And each one had an anecdote to relate. Auspicious and inauspicious- all was revealed. Finally someone happened to remember:

Let that swine Magan say few words. The chairman was all set to press the bell saying one, two, three, speak -

And Magan, the dolt, the poor idiot (one pities him) says (the same, what else?), he says (and this after receiving the prize for poetry), says I want to live. I want to love.

I want to write a poem.

(From Nissim Ezekiel \& Meenakshi Mukherjee, eds. 1991. Another India: An Anthology of Contemporary Indian fiction and poetry; Penguin. Pp 221-4)

\subsubsection{Dimensions of differences}

The other possible source of loss is in such pairs of languages that are different in langue as well as parole, i.e. in both structure and use. Such differences may occur at any level. For instance, at 
the lexical level, the differences may be in different dimensions such as follows:

(a) formality of styles available (frozen to completely informal),

(b) affectivity that any given text can achieve in the two languages (no reaction to overreaction),

(c) how general or technical these languages can be/become, and

(d) how are the texts evaluated in these languages (in terms of morality, pleasure, intensity or coverage?)

Let us consider the problem of style first. We will take a few texts to show that it will not be an easy decision for a translator in any one of our Indian languages to decode the particular style used in them accordingly decide as to how best to convert it into our languages:

\section{Text 8: The Original (Kipling: The Beginning of Armadillos, p 70)}

"But I am tortoise," said Slow-and-Solid,

"Your mother was quite right. She said that You were to scoop me out of my shell. Begin."

"You didn't say she said that a minute ago," said the Painted Jaguar. "You said, she said something different."

"Well, suppose you say that I said that she said something different. I don't see that it makes any difference; because if she said what you said I said she said, it's just the same as if I said what I said she said. On the other hand, if you think she said that you were to uncoil me with a scoop, instead of pawning me into drops with shell, I can't help it, can I?"

"But you said you wanted to be scooped out of your shell with my paw", said Painted Jaguar.

"If you'll think again, you'll find that I didn't say anything of the kind. I said that your mother said that your mother said 
that you were to scoop me out of my shell", said Slow-andSolid.

\section{Text 9: The Original (James Joyce's Ulysses; pp 56-7)}

On the door step he felt in his hip pocket for the latch key. Not there. In the trousers I left off. Must get it. Potato, I have creaky wardrobe. No use disturbing her. She turned over sleepily at that time. He pulled the hall door after him very quietly, more till the foot leaf dropped gently over the threshold, a limp lid. Looked shut. All right till I come back anyhow.

Notice that such problems exist in all languages. Anyone who dares translating similar authors who wrote in Indian languages into a western language, would soon realize the difficulties in deciding what the nearest equivalent to the style used in these texts should be.

This also brings us to the fourth point: Even if we neglect the private meanings, the original author and the translator may have completely different value systems and different semantic maps with which they operate. Therefore, there are bound to be losses or gains in the domain of semantics of the text(s) being subjected to any translating activity. We are reminded of the translation of the following verse from Amarushataka, 49:

\section{Text 10A: The Original (Sanskrit)}

nabhasi jaladalakSmiim saasrya viikSya drSTyaa pravasasi yadi kaantey ardham uktvaa kathamcit mama paTam avalambya prollikhanti dharitriim yad anukrtavatii saa tatra vaaco nivrttaaH!

It was translated by W.S.Merwin and L.Moussaieff Masson 1981:89 (in their anthology The Peacock's Egg) in the following way:

\section{Text 10B: Translation}

Lush clouds in dark sky of tears she saw my love 
if you leave me now she

said and could not say more

twisting my shirt

toe gripping dust

after that what she

did all words

are helpless to repeat and

they know it and give up

It is obviously a very different task for any translator to do justice to these lines in Sanskrit. It may also be difficult for the TL readers to appreciate these sentiments because of a huge difference between the way man woman relation unfolds in our culture and the way it works in the west. But one must still appreciate the strategy used by the translators in attempting to render the piece in English where they made several changes:

(i) they altered the line divisions,

(ii) they opted for a free verse style,

(iii) they took recourse to italicisation/underscoring to identify the incomplete sentence spoken by the woman, and

(iv) made lexical adjustments, such as paTam $>$ shirt, etc.

\section{Genetically unrelated languages and translation}

Translation presents special problems for languages that are genetically unrelated or typologically different. The reason is obvious. The constraints which crop up when one contrasts two such languages are the real problems in the process of translation to be tackled by any comprehensive theory, particularly if one reiterates faith in Jakobson's words that equivalence in difference is the cardinal problem of language and the pivotal concern of linguistics. There is no doubt that total translation is replacement of SL grammar and lexis by equivalent TL grammar and lexis with consequential replacement of SL phonology, graphology by (nonequivalent) TL phonology/ graphology. Catford's hypothesis may be validated only when differential bilingual dictionaries with a careful comparative definition of all the corresponding units in their 
intention and extension become handy. Likewise referential bilingual grammars should define what defines and what differentiates the two languages in their selection and delineation of grammatical concepts.

A scientific investigation is warranted to study the typological differences and peculiarities in translation. Nama observes that the translator or mediator between two different linguistic systems is compelled to resolve a good number of obstacles. The success or failure of a translation mainly depends upon how far and how best the translator resolves these obstacles. Translators themselves do not find it true that the notion of equivalence can be achieved through various replacement processes between pair of languages. In 'Language, Structure and Translation', Eugene Nida remarks:

"...a careful analysis of exactly what goes on in the process of translating, especially in the case of source and receptor languages having quite different grammatical and semantic structures has shown that, instead of going directly from one set of surface structures to another, the competent translator actually goes through a seemingly roundabout process of analysis, transfer and restructuring. That is to say, the translator first analyses the message of the source language into its simplest and structurally clearest forms, transfers at this level, and then restructures it to the level in the RECEPTOR language which is most appropriate for the audience which he intends to reach...."

\subsection{Cultural differences}

As mentioned already, the problem of genetic unrelatedness or structural distance becomes more difficult to deal with where there exists cultural differences in addition to linguistic differences. It should not be surprising to find A.K. Ramanujan not translating the tile of U.R. Ananthmurthy's Samskaara, even though he does translate the word differently in the text. Similarly, Radhakrishnan's retention of the word dharma in his translation of the Gitaa in certain contexts in his English text is justified on the same grounds.

Let us take up the example of Jayashankar Prasad's Kaamaayanii and its well-known structuration into 15 cantos: 
Cintaa; aashaa; shraddhaa; kaam; vaasanaa; lajjaa; karma; iirSyaa; iRaa; svapna; sangharSa; nirveda; darshana; rahasya; aananda

Anybody familiar with the Indian philosophical thoughts will realize that many of these words are difficult to translate in that they will have many renderings each in any western language. In one of the several translations of this classical text, Jaikishandas Sadani 1975 opts for the following:

Anxiety; hope; faith; passion; bashfulness; action; envy; intelligence; dream; struggle; renunciation; revelation; mysticism; bliss

While there will be general agreement on some of these renderings as the one for.svapna, sangharSa, etc., for many others, one doubts if the choice is acceptable taking the full connotation of such words. Take, for instance, the following naming words each one of which has so many interpretations in English:

Shraddhaa: reverence; respect; faith; trust; confidence; regard; esteem; admiration.

Karma: action; deed; work; function; occupation; fate; rite; ceremony; affair.

If these options with reasonably different meanings or different semantic shades in the source language, it seems difficult to choose any one item in the TL.

To further re-emphasize the problems that typically emerge out of language pairs that are unrelated, let us look into the last stanza of Kaamaayanii, and compare a few translations. This argument will find further support. Consider the following lines:

\section{Text 11A: The Original (Hindi)}

samaras the jaR yaa cetan

sundar saakar banaa thaa;

centantaa ek vilastii

aanand akhaND ghanaa thaa.

Let us now look into the different renderings that are available: 


\section{Text 12A: Translation 1 (Jaikishandas Sadani)}

Matter and spirit are harmonious

Exquisite was the form of beauty

Consciousness alone was blossoming

Transcendental infinite Bliss.

\section{Text 12B: Translation 2 (B.L. Sahney)}

All objects conscious or conscious were

Pervaded by the savour of one life,

And beauty was incarnate everywhere,

And Bliss intense and undivided reigned.

\section{Text 12C: Translation 3 (D.C. Datta)}

Spirit and matter both seemed one, Assuming beauties fresh and new;

One consciousness pervaded all

And joy from heaven dropped like dew.

\section{Text 12D: Translation 4 (Rameshwar Gupta)}

Spirit and matter joined,

Beauty took form,

One consciousness sported round,

It was intense unbroken bliss.

While the fourth translation seems, unduly concise, the second option is the opposite: in P.Lal's words, this one seems to be "an amplified interpretation more than a translation". The third one suffers from the defect of introducing new elements merely for metrical reasons: 'dew', for instance; or even 'heaven'. These do not find mention in the original given above. The options given here for the Hindi words $j a R$ and cetan again show the similar problems I realised earlier. In $12 \mathrm{~A}, \mathrm{C}$ and $\mathrm{D}$, the choice is unanimous: spirit and matter for cetan and jaR, respectively.

\subsection{Typological differences}

An understanding of the structural complexity and typological distance along with its socio-cultural context among the languages is indeed useful in determining translation equivalence. Further this 
will be of more help to translators to orient their actions and develop theories on an empirical foundation. For instance, English represents the SVO pattern and Tamil the SOV pattern of languages. The shift from one to another is possible and permissible in the process of translation but as a student of Translation Studies, one must find out whether in doing so there are a set of constraints that hinder the smooth transference or translation.

\section{Summary}

The main purpose of this essay was to make one aware of the fact that it is not at all unusual to enjoy the literary creativity of authors writing in distant socio-cultural environments in one's own language, but that one must be aware of the inherent difficulties with such third literatures.

\section{Notes}

1. They are not strictly comparable though. But recall the position taken by Tirumalesh in treating translated texts as equivalent to any original text written in either of the two languages (source and target) in question, a phenomenon which he calls 'Translation as Literature Three', which remains on par with two indigenous literary traditions.

\section{References}

Basnett, Susan \& Andre Lefevere 1993 "General Editors' Preface" In Gentzler. Pp ix-X.

Fitzgerald 1851. "Letter to the Rev. Cowell", dated $22^{\text {nd }}$ March, as quoted in Basnett McGuire's 1980 Translation Studies. P 3.

Gentzler, Edwin 1993 Contemporary Translation Theories London and New York: Routledge \& Kegan Paul.

Richards, I.A. 1929 Practical Criticism New York: Harcourt Brace.

Trivedi, Harish 1992 Omar Khayyam in India: An evolution through Persian, English and Hindi, in Papers in Comparative Literature, 2: The Aesthetics of Translation (ed) by Amiya Dev. Calcutta: Jadavpur University. 
K.Satchidanandan 1984 Translating Poetry tr. By E.V. Ramakrishnan, Chandrabhaaga II, Vol. 11, summer, pp. 3940 . 